\title{
La memoria convocada. Acerca de la entrevista en historia oral
}

\author{
Jorge E. Aceves Lozano
}

CIESAS-OCCIDENTE

\begin{abstract}
Uno de los aspectos centrales en la práctica de la historia oral es la cuestión de la memoria. En este escrito se discute el papel que ella tiene en la situación de la entrevista y la manera en que podemos trabajarla en sus diversos ámbitos de carácter individual, colectivo y social.
\end{abstract}

"...del pasado, la memoria no retiene más que la espuma." P. Chaunu

"...la memoria no busca salvar el pasado más que para servir al presente y al futuro." J. Le Goff

"la memoria es la vida." P. Nora

“...tanto más poderoso es mi terror al olvido que el temor de tener que recordar demasiado." Y. Yerushalmi

omo practicantes y partícipes del movimiento de la historia oral el problema, o si se pre- fiere, la "cuestión" de la memoria es un asunto de la mayor relevancia heurística, metodológica y analítica que se nos puede presentar. Tanto como objeto de investigación, cuya importancia al parecer ha llegado a constituir una moda, como por constituir la materia primaria que nutre las nuevas fuentes de la historia oral contemporánea, la memoria es un excelente pretexto para abordar reflexivamente el proceso de construcción de las fuentes orales y el papel que juega en la misma.

Ahora no me ocuparé de la memoria como objeto de investigación pri- 
vilegiado, ${ }^{1}$ ya que enfocaré la manera como el historiador -o cualquier investigador interesado en el contenido manifiesto en la oralidad-, puede hacer aflorar, conocer y examinar el contenido de la memoria oral que se expresa mediante la situación particular de la entrevista.

Puesto que al trabajar con los relatos orales estamos afianzando nuestra investigación en los procesos de la memoria y el olvido, en la evocación y el recuerdo, en los procesos subjetivos de selección y discriminación de lo vivido, o sea, cuando desde el presente es posible resignificar el pasado representado, los narradores son una matriz compleja de producción de sentido que se expresan a través de la memoria. Y lo que ésta cuenta no es la resurrección de las experiencias reales, sino reconstrucciones y versiones de lo vivido/acontecido. La memoria recupera y retiene lo que le ha parecido más relevante preservar y transmitir.

Los testimonios de la memoria no sólo narran hechos, también aportan formas de ver y pensar el mundo, valores, creencias, inquietudes, anhelos y una variedad de ideas $\mathrm{y}$ actitudes que acompañaron su vida en el pasado. Al

\footnotetext{
${ }^{1}$ Algunos estudiosos e impulsores de la memoria como objeto de estudio en ciencias sociales y la historia han sido, por ejemplo, y no sólo: H. Bergson, M. Halbwachs, P. Nora, E. Hobsbawm, J. Le Goff, R. Chartier, P. Thompson, A. Portelli, Ph. Joutard, L. Passerini, R. Grele, G. Namer, F. Yates, Y. Yerushalmi, P. Bertrand, J. Vansina, F. Raphael, Y. Lequin, J. Pujadas, E. Bosi, D. Middleton y D. Edwards, J. Cuesta, etcétera.
}

desplegarse la memoria se reproducen prácticas y representaciones que involucran no sólo al individuo y su microentorno, sino también al entorno de colectividades más amplias. Ya que la manera como las personas recuerdan el pasado, describen su presente y vislumbran su futuro, está persistentemente enmarcada por el entorno social de su existencia y de su ubicación social.

El recuerdo del pasado está siempre filtrado por las circunstancias del presente y será reevaluado, reasumido y resignificado como parte de los procesos dinámicos de toda colectividad. Por su pertenencia al grupo social es que los individuos son capaces de adquirir, almacenar y transmitir sus memorias. En el campo de acción de la historia oral, es en la situación de la entrevista, y en sus distintos momentos de desarrollo, donde la memoria entra directamente en juego.

El momento en que se produce la conversación es el punto central del trabajo de construcción de las nuevas fuentes orales y es donde se concreta la comunicación entre el memorista y el historiador. No es el único momento, como se sabe, ya que la fase previa, la del encuentro, es determinante para el desarrollo de la situación de la entrevista y sus contenidos. Después del momento de la conversación, orientada por la intervención del historiador, continúa una tercera fase, que es la del análisis y descubrimiento de los contenidos de la memoria del relator.

De tal modo que las tres fases sucesivas de: $a$ ) encuentro, $b$ ) conversación y c) descubrimiento analítico, son las que permiten la construcción de las 


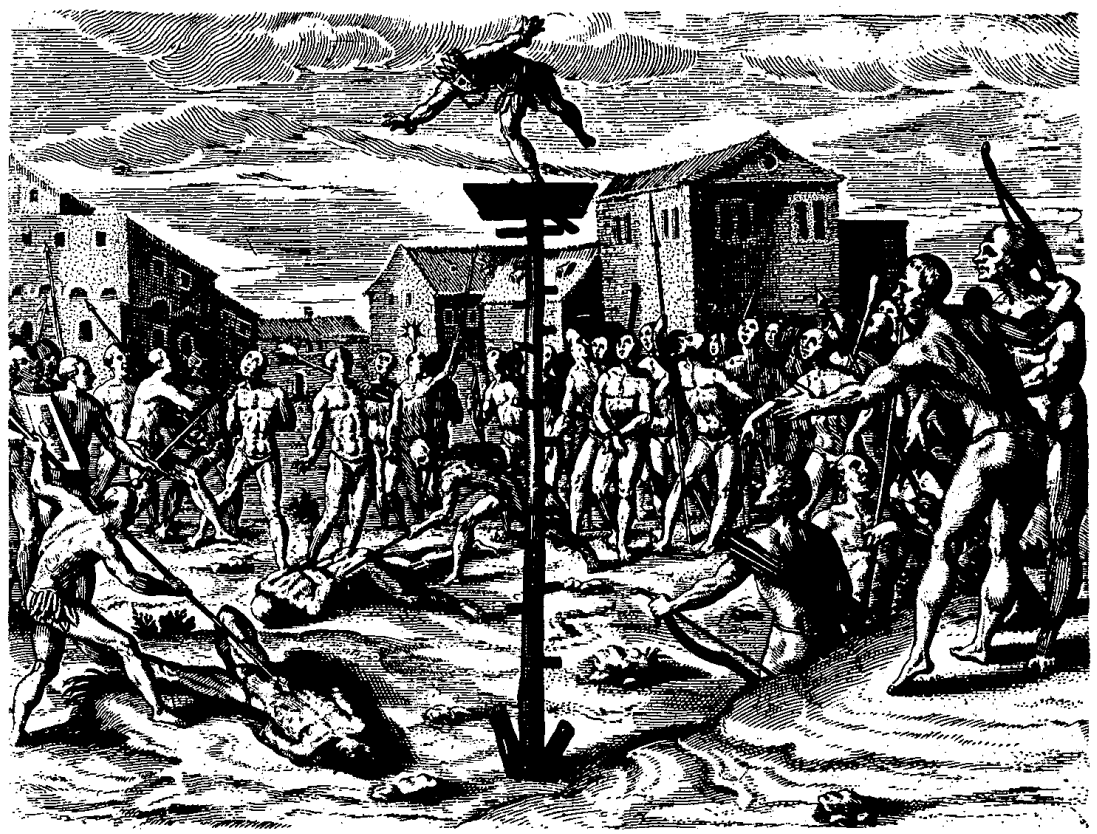

que podríamos denominar como fuentes vivas de la memoria. Cada una de las fases afecta la manera como, desde el punto de vista del narrador, es posible hacer aflorar los contenidos de su memoria. En la historia oral y en aquellos interesados en los enfoques biográficos, la entrevista busca encontrar la versión y visión propia de los actores sociales, que recoge a través de la viva voz de sus protagonistas; no obstante interviniendo y modulando la conversación con el fin de orientarlos hacia un tema, evento, vivencia o proceso específico, que bien puede ser acotado (life-stories) o tan amplio como es una historia oral de vida(lifebistory) ${ }^{2}$

En la entrevista oral nos enfrentamos en primer término con la necesidad de hacer surgir la memoria individual. Estamos entrevistando a personas que son únicas e irrepetibles, cuyas vivencias y recuerdos tienen sentido y contenidos específicos que no necesariamente son parecidos al patrón social o cultural más amplio; lo que no implica dejar de lado el hecho

2 Véase Denzin, "Life", 1977; Bertaux, "Relatos", 1993, pp. 136-148, y "Enfoque", 1988, pp. 55-80. 
de que está inserto en un grupo social más amplio. Entonces, el entrevistador se enfrenta a un panorama nuevo y sus guías de temas, sus recetarios técnicos y metodológicos no siempre van a poder ofrecerle una ayuda útil y oportuna. El entrevistador tiene entonces que innovar, adaptarse, inventar y resolver la situación antes y durante la producción de la conversación.

Antes, porque la manera como se ha acordado el ritual de la entrevista, la manera como se ha presentado el propio investigador, la forma como se explicó el objetivo de la entrevista, el uso que se le va a dar, el público potencial receptor de los resultados de la investigación, en fin, todo lo pertinente debe ser conocido antes por el narrador de memorias personales. Esto crea expectativas, temores, emociones diversas; algunas útiles para que la memoria se organice y aparezca más clara y organizada, otras son obstáculos que más bien coordinan los silencios y facilitan los olvidos. Por ello, la etapa del encuentro entre el entrevistador y el narrador de sus memorias, sus relatos personales, su historia de vida, es muy importante como factor que influye en la fase de la conversación y las condiciones requeridas para elaborar, reconstruir y recoger la memoria oral y personal de los narradores.

Esa etapa del encuentro es condicionante de las siguientes fases de la situación de la entrevista, ya que nosotros partimos de que la memoria es una construcción del recuerdo con base en las experiencias pasadas, sean personales, colectivas o sociales. En la situación de la entrevista, en su momento de la conversación, es donde afloran los diversos contenidos y formas de la memoria. Pero de entrada, lo que nos interesa en la entrevista es aquella memoria personal, individual, para luego discernir y rastrear los elementos de la colectiva y aun de la social en la última fase, la del análisis y del descubrimiento. En síntesis, la memoria "está en el corazón de una dialéctica sutil entre ayer y hoy, entre la colectividad[...]los grupos y los individuos que la componen".

En cuanto a la memoria individual, coincido con cierta definición que afirma que en el sentido más simple significa la presencia del pasado en el narrador. Aquélla "es una reconstrucción psíquica e intelectual que supone...una representación selectiva del pasado...que no es nunca el del individuo solo, sino el de un individuo inserto en un contexto familiar, social, nacional". "La memoria colectiva, por otro lado, es un ingrediente inocultable de la memoria individual y podríamos definirla como "...el recuerdo, o el conjunto de recuerdos, concientes o no, de una experiencia vivida y/o mitificada por una colectividad, alimentada por una identidad de la que el sentimiento del pasado es parte integrante". 5

Tanto la memoria individual -la de la persona- como la colectiva -la del

\footnotetext{
${ }^{3}$ Crubelier, cit. en Cuesta, "Memoria", 1996, p. 76.

"Véase Rousso, "Mémoire", 1993, pp. 105 y ss., cit. en Cuesta, "Memoria", 1996, p. 59.

"Véase Nora, cit. en Cuesta, "Memoria", 1996, p. 61.
} 
grupo- pertenecen al ámbito de la memoria social, que reside en y es producto de la sociedad, independiente $y$ sin el soporte de ningún grupo. No sería la suma de las memorias colectivas, sino más bien una especie de sustrato o residuo de las memorias colectivas, con su contenido y dinámica propios. Siguiendo a M. Halbwachs, cuando define esto como los cuadros de la memoria social afirma que

...todo recuerdo, aun el más personal [...] está en relación con todo un conjunto de nociones que muchos otros también poseen, como personas, grupos, lugares, fechas, palabras y formas del lenguaje, de razonamientos y también de ideas, es decir, con toda la vida material y moral de las sociedades a las que pertenecemos o hemos pertenecido. ${ }^{6}$

De esta forma, con los tres tipos de memoria identificados en el proceso y situación de la entrevista oral, los recuerdos fluyen propiciados y condicionados por las esferas de influencia $\mathrm{y}$ ámbitos de referencia de estos tipos de memoria.

Sin embargo, las representaciones del pasado no van a ser compartidas en los mismos términos por toda la colectividad. Ya que es desde el tiempo presente y desde las condiciones $y$ situación de la entrevista oral que se evocan los recuerdos y se arma el discurso del narrador. Ya que también.

...evocamos la memoria con preguntas precisas, con curiosidades que tienen

${ }^{6}$ Halbwachs, cit. en Cuesta, "Memoria", 1996 , p. 60. una finalidad y deseos radicados en el presente. Y la memoria nos restituye un pasado seleccionado a partir de estas cuestiones, de estas curiosidades y de estos deseos. Ni siquiera el montaje del conjunto de recuerdos es espontáneo, porque para hacerlo son necesarios modelos culturales que hagan posible un desciframiento significante de ellos. ${ }^{7}$

En la entrevista, gracias a esa presencia e intercambio de subjetividades en los interlocutores, en el narrador ocurre una situación particular al reseñar su vida (life-review) que hace que al evocar los contenidos de su memoria éstos corran de acuerdo con los convenios y negociaciones entablados para la entrevista con el investigador. La selección no necesariamente se convierte en olvido, sino que adquiere más propiamente el sentido de incluir silencios estratégicos. Reseñar la vida propia es destacar y discriminar las vivencias comunicables frente a otras no aptas para ser transmitidas, compartidas, evocadas. La ruptura con el pasado no sólo pasa por la memoria existente, sino también por los silencios voluntarios y los olvidos que reproducen la amnesia. Darse cuenta de esto, descubrirlo, es quizá una tarea y un reto para el investigador en la tercera fase, la analítica.

Los entrevistadores -historiadores orales y demás- buscamos esas historias contadas por la memoria con la finalidad de construir otro tipo de discurso: el que corresponde a una disciplina y práctica científica. No obstante, las relaciones entre la memoria y la p. 61 .

${ }^{7}$ Peyrot, cit. en Cuesta, "Memoria", 1996, 
historia son profundas y no hay fronteras muy precisas que las desliguen. A la historia le importa el conocimiento, a la memoria la comunicación de lo vivido. La memoria es la relación de las vivencias, la historia es el discurso acerca de esos acontecimientos, pero desde fuera de los mismos. La memoria es parte, está en el seno del acontecimiento. Y no sólo es esto, es también una porción viva que es parte del narrador; por lo que llamarlo nuestra fuente viva tiene sentido en el proceso de investigación.

No obstante, recuperar la memoria no sólo puede tener sentido para un quehacer disciplinar, ya que socialmente implica una activación y una posibilidad para propiciar procesos identitarios. Ya que traer la memoria al presente tiene un doble valor:

...sistematiza, ordena y recupera para el grupo, mediante la incorporación de los recuerdos individuales fragmentados y fragmentarios, los orígenes, condiciones y factores que han llevado a la situación actual vivida por el grupo, a la vez que recobra, devela, descubre para el individuo y también para el grupo, el origen de su posición dentro del mismo, de sus actitudes, de sus temores, deseos, creencias y de su forma de relacionarse dentro de él y con el mundo circundante, como miembro de la comunidad. ${ }^{8}$

Trabajar con la memoria implica partir de esa historia vivida para concluir con una historia relatada. Transición que ocurre por intermediación de los procesos selectivos, de silencia-

${ }^{8}$ Montero, "Memoria", 1990, p. 33. miento voluntario, de olvido voluntario o pasivo, ${ }^{9}$ de una manera personal de organizar la comunicación y jerarquización de los hechos y experiencias por relatar; influida también por un construcción lógica del individuo salpicada por la curiosidad, el interés, el estilo, el temperamento, el contexto familiar-escolar-mass mediático, etc., del narrador en su relación de interpelación o conversación dialógica con el entrevistador (el historiador oral).

Porque es bien sabido que más que una memoria almacenada y lista para exhibirse íntegra y sistemática, de los narradores se obtiene el resultado de una mezcla de todos los datos que se recogen, en una composición regularmente digerida, en constante dinamismo y en transformación. La memoria cambia al paso de los años y del tiempo, es por tanto un producto social y cultural no inerte, cuestión que debe considerarse especialmente en la situación de la entrevista, ya que no van a interesar en primer término aquellas memorias curriculares y oficiosas, reelaboradas constantemente para moldear y reconstruir la figura social del personaje. Sin embargo, tampoco es posible pretender recoger y comprender la memoria absoluta, como tam-

\footnotetext{
${ }^{9} \mathrm{Y}$. Yerushalmi se refiere al olvido “...en el sentido colectivo... cuando ciertos grupos humanos no logran -voluntaria o pasivamente, por rechazo, indiferencia o indolencia, o bien a causa de una catástrofe histórica que interrumpió el curso de los días y las cosas- transmitir a la posteridad lo que aprendieron del pasado". El principio es que no se olvida lo que antes no se ha recibido. Los pueblos y grupos sólo pueden olvidar el presente, y no el pasado. Véase Yerushalmi et al., Usos, 1989, pp. 13-26.
} 


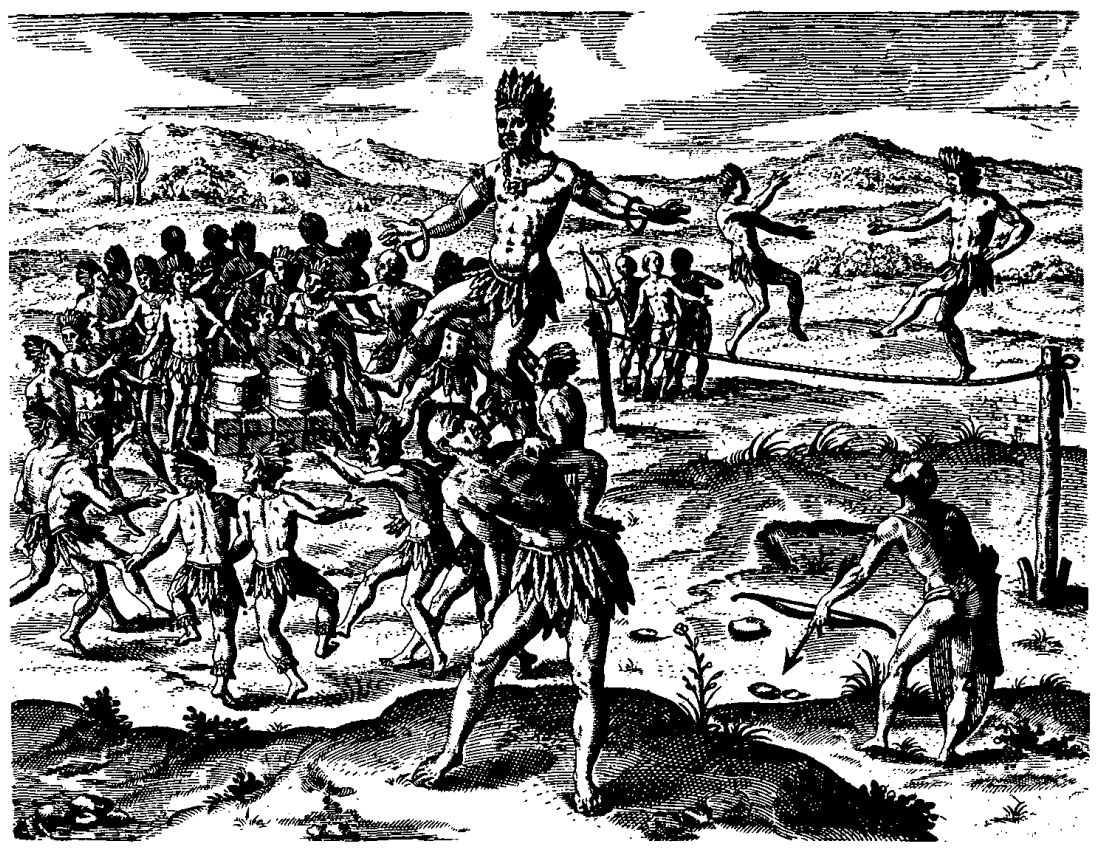

bién es improbable constatar el olvido total. ${ }^{10}$

En esta frontera memoria/olvido también aparece la relación entre la memoria y el mito, o sea cuando los recuerdos del memorista mo tienen un anclaje en un tiempo y espacio preciso y concreto, sino que navegan en el profundo pasado. No abundaré en este asunto en este trabajo, sólo quiero señalar que la evocación de la me-

${ }^{10}$ Josefina Cuesta, en una comparación inspirada, recuerda al "desmemoriado" Don Quijote por un lado, y al super memorioso "Funes", personaje de Borges. Véase Cuesta, "Memoria", 1996, p. 58. moria en la situación de la entrevista no escapa del juego de los tiempos. El recuerdo puede estar cargado de nostalgia, de idealización, de encarnación de imaginarios y creación de figuras y héroes reencontrados al hurgar en el pasado personal y colectivo. Y no sólo la recreación y generación de mitos es una tarea frente al olvido, también la necesidad de la memoria puede imponerse como una necesidad o tarea colectiva. La memoria entonces se cultiva como recurso de identidad y aun para la supervivencia. ${ }^{11}$

${ }^{11}$ Por ejemplo, el caso de Amnistía Internacional, el Informe Sábato, textos sobre la gue- 
Al referirnos a la memoria como un recurso colectivo, es claro que las memorias resultantes son diversas, plurales y frecuentemente no coincidentes. Siempre hay tensión social en la procuración y trasmisión del recuerdo pasado. Por lo cual, sólo metafóricamente podemos referirnos a la memoria de un pueblo, de una nación; ya que los propios memoristas orales son parte de grupos y colectividades diferenciadas y con historias propias. Esto nos lleva a reconocer diversos géneros o tipos de memorias que trazan los mapas y rutas de las memorias colectivas existentes y que se remontan hacia los tiempos pasados. Memorias familiares, memorias de grupos, memorias de compañeros de catástrofes, de hechos imborrables a las memorias individuales, memorias generacionales, o bien memorias de clase, etnia, género, territorio, etcétera.

El individuo tiene y reproduce una memoria en el ámbito colectivo, en la relación con los demás, en el proceso de compartir y comunicar su experiencia. Diríamos en resumen, que sólo conectada en las relaciones sociales aparece y se manifiesta una memoria propia, personal, colectiva y social.

Por todo lo anterior, en la entrevista de historia oral se presenta la ocasión para incursionar en los caminos, y a veces en los laberintos, de la memoria de las personas. El resultado de la entrevista será un texto que narra los recuerdos y los testimonios personales de los narradores. Su memoria lo hizo posible, su memoria los con-

rra Civil española y del holocausto nazi, etc. Véase, Cuesta, "Memoria", 1996, pp. 65-66. vocó, su memoria pudo aflorar a la superficie también y gracias a la conversación y a la gestión de un acuerdo adecuado de la situación de la entrevista. El entrevistador habrá puesto de su parte otras cosas, como ciertas técnicas, su orientación temática, su inquisitiva curiosidad, su amable figura profesional, etc., pero nunca la historia vivida. Ésta es la que tiene que comprender, examinar y analizar, para poder proponer una diferente lectura de ese texto de la memoria evocada y recogida; y entonces desarrollar su propio oficio en la elaboración de su versión de esa historia.

\section{BIBLIOGRAFÍA}

-Bertaux, D., "El enfoque biográfico: su validez metodológica, sus potencialidades" en Ph. Joutard et al., Historia oral $e$ bistorias de vida, FLACso, Costa Rica, 1988, pp. 55-80 (Cuadernos de Ciencias Sociales, 18).

análisis social" en J. Aceves (comp.), Historia oral, UAM/Instituto Mora, México, 1993.

-Cuesta, Josefina, "De la memoria a la historia" en A. Alted (coord.), Entre el pasado y el presente. Historia y memoria, UNED, Madrid, 1996.

-Denzin, N., "Life history method"en The research act. A theoretical introduction to sociological methods, McGraw Hill, Nueva York, 1977.

-Montero, M., "Memoria e ideología. Historias de vida: memoria individual y colectiva", Acta Sociológica, UNAM, núm.1, enero-abril, 1990, México.

-Rousso, H., "La mémoire n'est plus ce qu'elle était" en Ecrire l'bistoire du temps presents, CBRS eds., París, 1993.

-Yerushalmi, Y. et al., Usos del olvido, Ed. Nueva Visión, Buenos Aires, 1989. 